\title{
Sodium Tetradecyl Sulfate Sclerotherapy for Venous Malformation of the Tongue: A Single-Center Experience
}

\author{
Alfred Inbaraj ${ }^{1}$ Shyamkumar Nidugala Keshava' Vinu Moses $^{1}$ George Koshy ${ }^{1}$ Munawwar Ahmed ${ }^{1}$ \\ Suraj Mammen ${ }^{1}$ Dheepak Selvaraj ${ }^{2}$ Prabhu Premkumar ${ }^{2} \quad$ Ashish Kumar Gupta $^{3}$ Sunil Agarwal ${ }^{2}$
}

${ }^{1}$ Department of Radiology, Christian Medical College, Vellore, Tamil Nadu, India

${ }^{2}$ Department of Vascular Surgery, Christian Medical College, Vellore, Tamil Nadu, India

${ }^{3}$ Department of Plastic Surgery, Christian Medical College, Vellore, Tamil Nadu, India

J Clin Interv Radiol ISVIR 2018;2:76-82

\author{
Address for correspondence Shyamkumar Nidugula Keshava, \\ DMRD, DNB (Radiology) FRCR, FRANZCR, Department of Radiology, \\ Christian Medical College, Ida Scudder Road, Vellore 632004, \\ Tamil Nadu, India (e-mail: aparna_shyam@yahoo.com).
}

\begin{abstract}
Keywords

- tongue venous malformation

- sclerotherapy

- sodium tetradecyl sulfate

Purpose To study the safety and effectiveness of sclerotherapy with 3\% sodium tetradecyl sulfate (STS) in the management of venous malformation (VM) of the tongue. Materials and Methods The clinical and imaging data of patients with tongue VM treated with STS sclerotherapy over a period of 15 years (2002-2017) were reviewed. Safety was assessed based on the incidence of minor and major complications. Effectiveness was assessed by clinical improvement (reduction in symptoms and size) on a 10-point scale.

Results The study included 44 patients (26 men and 18 women). The median age was 24 years at the time of treatment. Eight patients were lost to follow-up. Four patients ( 4 of $44,9 \%$ ) had complications including venous bleeding needing compression, self-limiting hematuria, significant swelling of the tongue requiring prolonged intubation, and arterial bleeding due to injury to the lingual artery. Clinical improvement was seen in 30 (30 of 36, 83\%). The median clinical improvement was 4.5 on the 10 -point scale, with a range of 1 to 8 . Twelve ( 12 of $36,33.3 \%$ ) patients demonstrated 1 to $40 \%$ improvement in the lesion size and 18 (50\%) had 41 to $80 \%$ improvement. Conclusion Sclerotherapy with $3 \%$ STS is safe and effective in treating venous malformations of the tongue with minimal complications.
\end{abstract}

\section{Introduction}

Venous malformations (VMs) of the tongue occur due to defective vascular morphogenesis; hence they are present at birth but can manifest clinically at any age. ${ }^{\text {Similar to VMs }}$ in other locations, these are postcapillary lesions and exhibit slow flow. ${ }^{2}$ The lesions are soft, nonpulsatile, compressible, and position dependent. They often have a bluish tinge and enlarge in size on Valsalva's maneuver. ${ }^{3}$ They are responsive to hormones and may enlarge during physical exertion and pregnancy. ${ }^{4}$ These lesions cause cosmetic disfiguration, recurrent hemorrhage, and pain. They can also cause

received

June 5, 2018

accepted after revision

July 25, 2018

published online

August 17, 2018 functional impairment of speech, chewing, swallowing, and breathing. ${ }^{5}$ They progressively enlarge with age, fail to regress, and are a challenge to treat. ${ }^{6}$

The goal of therapy for symptomatic VMs of the tongue is to reduce the size of the malformation and conserve as much lingual tissue as possible. There are limited data on the management of tongue VMs. Treatment options include surgical excision, laser therapy, cryotherapy, radiotherapy, embolization, sclerotherapy, and medical treatment with interferon- $\alpha$ and steroids. ${ }^{2}$ These options are often combined to achieve optimal results. There are no comparative studies assessing the efficacy of these treatment methods.
Copyright $@ 2018$ by Indian Society of Vascular and Interventional Radiology
License terms

10.1055/s-0038-1669372.

ISSN 2457-0214. 


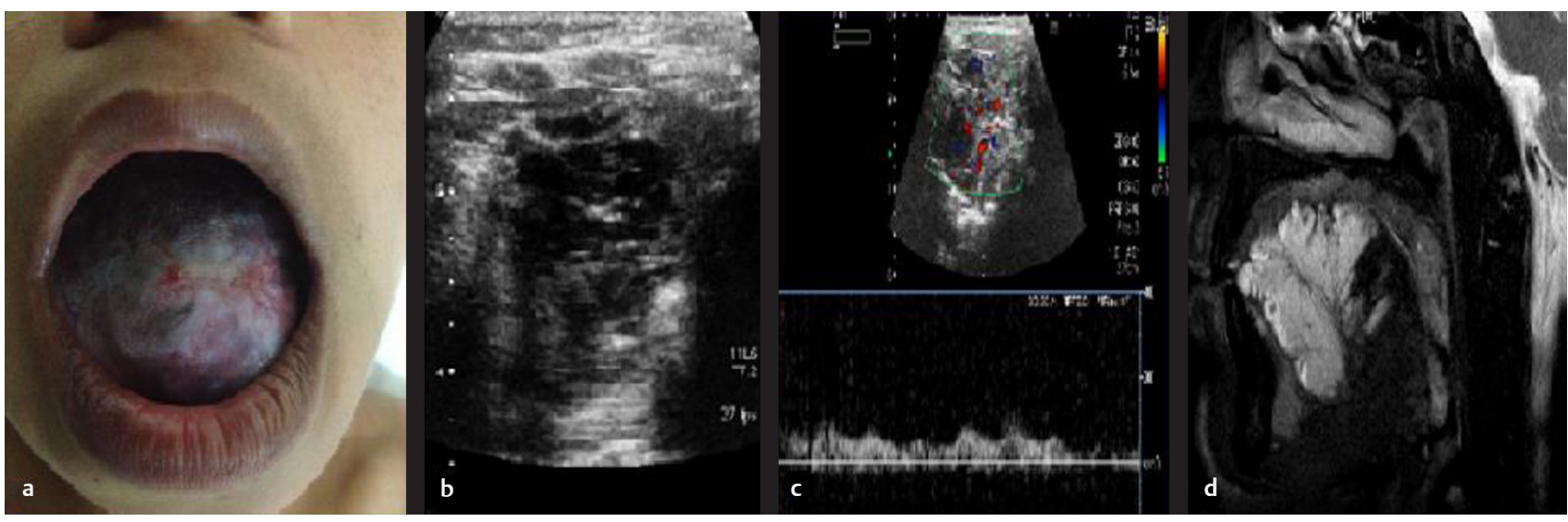

Fig. 1 A 17-year-old girl with venous malformation of the tongue presented with difficulty in speaking and swallowing. (a) A photograph of the venous malformation. There are enlargement, bluish discoloration, and fissuring of the tongue. (b) Grayscale ultrasound image showing venous spaces that were compressible. (c) Color-flow imaging and spectral Doppler evaluation demonstrating venous flow within the lesion. (d) T2W STIR sagittal image showing high signal of the lesion and a few hypointense foci suggestive of phleboliths.

Sclerotherapy is minimally invasive and inexpensive. Sodium tetradecyl sulfate (STS) acts by destroying the endothelial lining of the VM and coagulates the intraluminal blood resulting in obliterative thrombosis. ${ }^{78}$ This is followed by fibrosis and reduction in the lesion size. ${ }^{9}$ In this study, we report our experience on treating VM of tongue with sclerotherapy using $3 \%$ STS.

\section{Materials and Methods}

This retrospective study was approved by our institutional review board. The clinical and imaging data of patients with tongue VMs, treated with STS sclerotherapy over a period of 15 years (2002-2017) were reviewed. Data collected included patient demographics, presenting symptoms, number of treatment sessions, quantity of sclerosant, improvement, and complications. Improvement was assessed by reduction in the lesion size and symptom relief after a period of 1 year.

\section{Diagnosis}

The diagnosis of VM was based on history, clinical examination, and imaging findings on ultrasound (US) and magnetic resonance imaging (MRI) ( - Fig. 1). Clinical examination was performed to locate the lesion, determine its visible extent, and also to plan for access during the procedure. US evaluation was performed to confirm the presence of venous spaces that were amenable for sclerotherapy. All patients underwent MRI to confirm the diagnosis of VM and to define the extent of the lesion. The diagnostic features considered on MRI were high signal intensity on short tau inversion recovery (STIR) and T2-weighted sequence. The VMs were categorized based on the size. Lesions greater than $3 \mathrm{~cm}$ were considered large. Small lesions were less than $1.5 \mathrm{~cm}$. The lesions between 1.5 and $3 \mathrm{~cm}$ were considered medium in size. ${ }^{7}$

\section{Treatment}

All procedures were performed under general anesthesia. The venous spaces were accessed with or without ultrasonography (USG), using either a $23 \mathrm{G}$ scalp vein (SV) or $22 \mathrm{G}$
Chiba needles, such that the needle entered through the normal mucosa or the skin. When needed, the tongue was stretched outside using sponge-holding forceps covered with a gauze piece. Alternatively, a midline anterior suture was used avoiding area of the tongue involved by VM. If required, multiple needles were placed into different locations of the VM. The needles were confirmed to be within the venous spaces by observing free backflow of blood. Under fluoroscopic guidance, contrast material was injected through the needles to define the extent, volume, and pattern of venous drainage of the venous spaces. An equal volume of STS foam was considered for therapy. STS (3\%) was mixed with same quantity of air to form STS foam using two10-mL disposable syringes connected via a three-way (modification of the standard Tessari method). ${ }^{10}$ The STS foam was injected into the vascular spaces under fluoroscopic guidance using a blank roadmap ( - Fig. 2). The dose of STS was $0.5 \mathrm{~mL} / \mathrm{kg}$ up to a maximum dose of $20 \mathrm{~mL}$ per treatment.

\section{Postprocedural Management}

All patients who were extubated immediately after the procedure were observed in the recovery room until they became fully conscious. They were advised to hydrate well and were observed in the hospital for 6 hours. They were discharged after 6 hours if there were no complications. Patients with VMs involving the posterior third of the tongue or at a high risk for airway obstruction after the sclerotherapy were electively kept intubated in the intensive care unit (ICU) for up to 2 days postprocedure to ensure adequate airway.

\section{Follow-up}

All patients were seen every 3 months for clinical improvement and for planning subsequent treatment. During these visits, they were assessed clinically for reduction in the lesion size and relief of symptoms. An US evaluation was performed during every visit to evaluate the presence of venous spaces. Patients were counseled for further sessions of treatment. The study endpoint in terms of clinical improvement was at 1 year after treatment. 


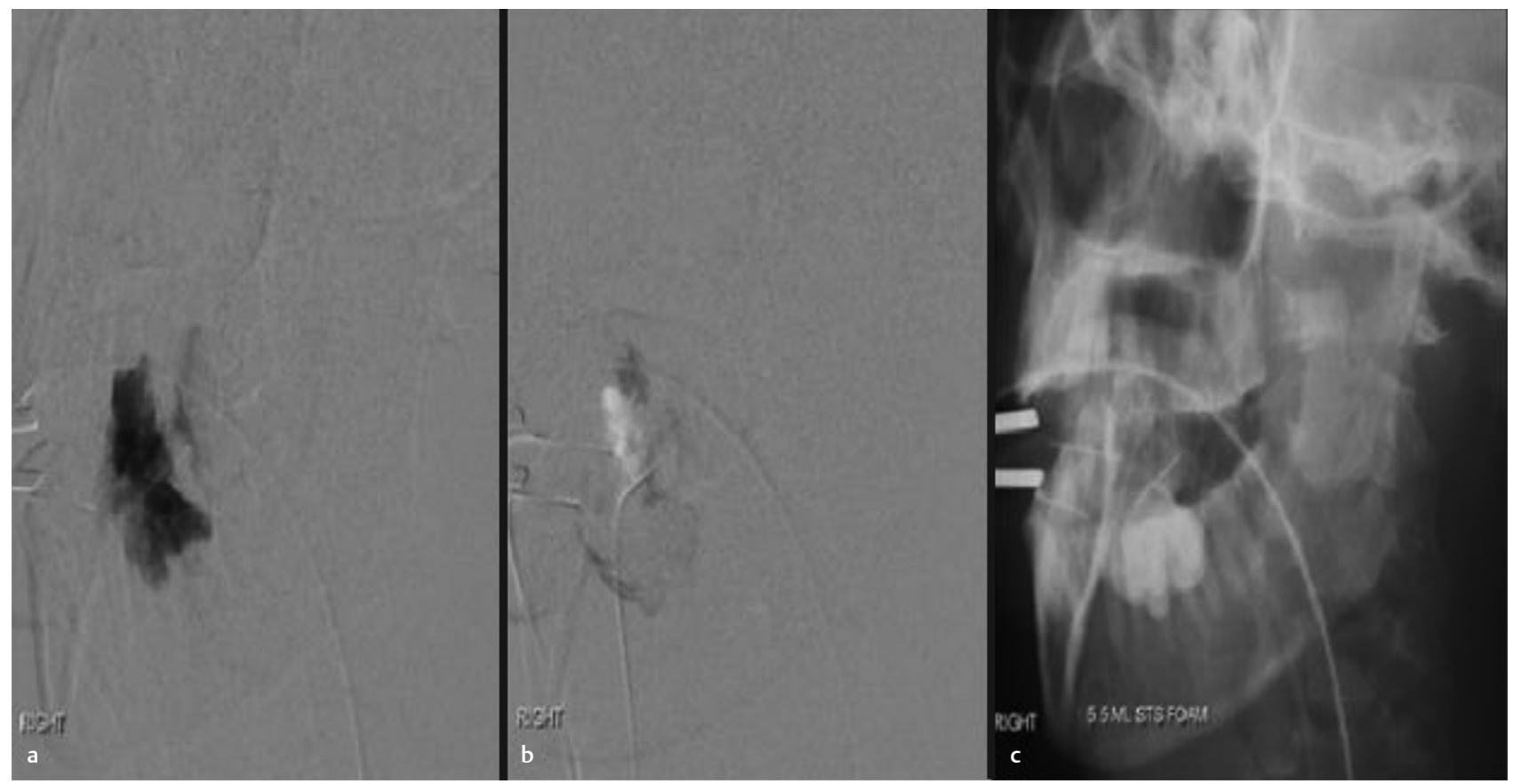

Fig. 2 A 23-year-old man with a venous malformation of left side of the tongue. (a) After inserting needles under USG guidance, contrast material was injected into the venous spaces to determine the amount of sclerosant to be injected. (b) Using blank road map, STS foam was injected into the venous spaces using 23G scalp vein needle. (c) A total of $5.5 \mathrm{~mL}$ of STS foam was injected into the tongue.

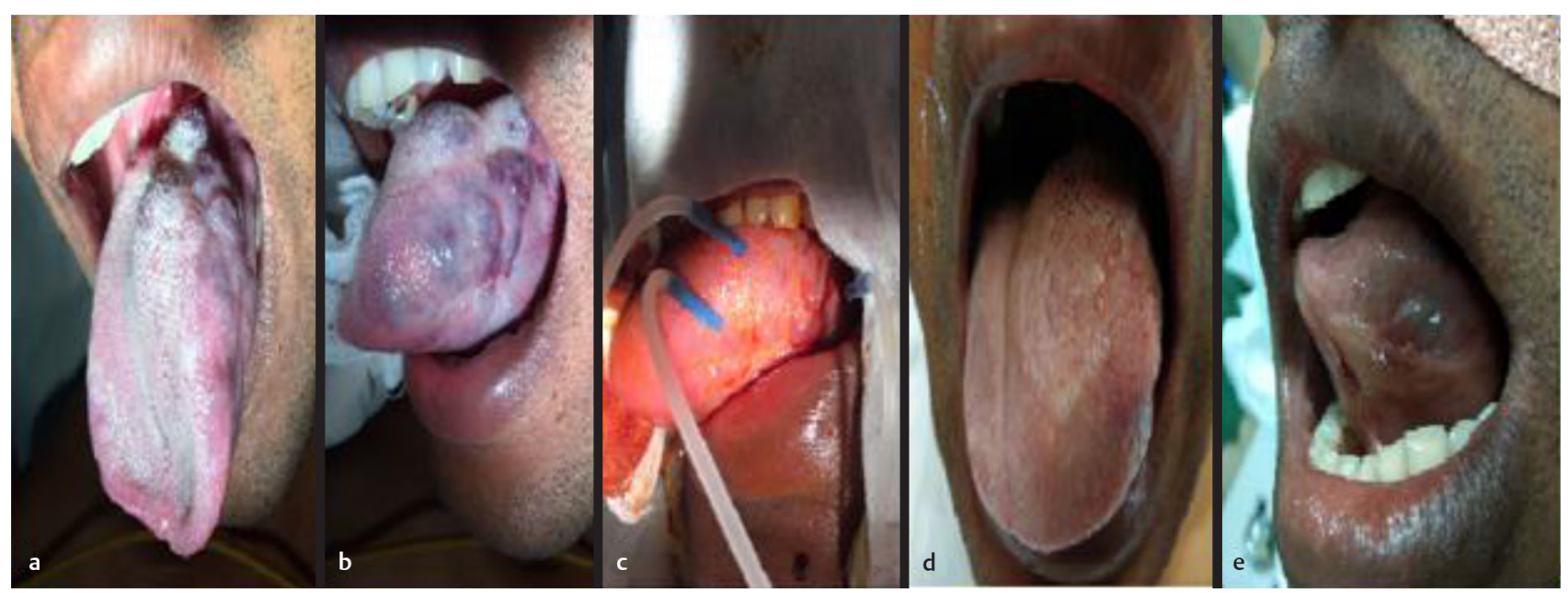

Fig. 3 A 30-year-old man with complaints of swelling over the left side of tongue since childhood with occasional episodes of bleeding. (a, b) Photographs demonstrating swelling of the left lateral aspect of the tongue. (c) Three scalp vein needles were inserted into the venous spaces. (d, e) Postsclerotherapy photographs showing significant reduction in the lesion size.

\section{Study Endpoints}

Any reduction in the lesion size was considered as technical success whereas relief of presenting symptoms was considered as clinical success. Both technical and clinical successes were taken as clinical improvement and graded together on a scale of 0 to 10 on follow-up after 1 year. The patients who could not follow up in person were assessed for clinical improvement through a telephonic conversation. Any technical or clinical success was considered as effectiveness of the procedure (-Fig. 3). The complications were graded according to the Society of Interventional Radiology (SIR) grading system. ${ }^{11}$

\section{Results}

Forty-four patients were included in this study. Twenty-six (59\%) were men and 18 (41\%) were women. The age ranged from 7 and 63 years. Most patients were in their second and fourth decades. Twelve patients were between 21 and 30 years. The median age was 24 years, whereas the mean age was 28.5 years. The most common clinical presentation was swelling of the tongue (41 of 44). The other predominant presenting symptoms were bleeding and pain. Of the 44 patients, 1 patient had an extensive abnormality that prevented complete closure of the mouth. Other symptoms 
Table 1 Tongue VM: presenting complaints

\begin{tabular}{|l|l|}
\hline Presenting complaint & Number of patients \\
\hline Swelling & 41 \\
\hline Bleeding & 10 \\
\hline Pain & 10 \\
\hline Difficulty in speaking & 6 \\
\hline Difficulty in swallowing & 3 \\
\hline Difficulty in breathing & 1 \\
\hline Difficulty in closing mouth & 1 \\
\hline
\end{tabular}

Abbreviation: VM, venous malformation.

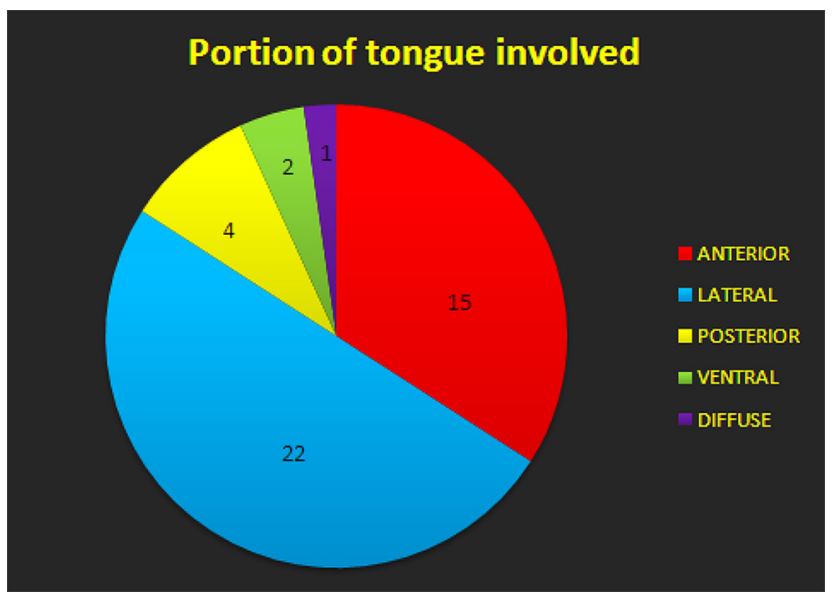

Fig. 4 Tongue VM: a pie chart demonstrating the frequency of involvement of various segments of the tongue.

such as difficulty in speech, swallowing, and breathing were less commonly seen ( $\boldsymbol{- T a b l e ~} \mathbf{1}$ ).

Twenty-five (56\%) patients had large $(>3 \mathrm{~cm})$ VMs, 10 had medium-sized $(1.5-3 \mathrm{~cm})$ VMs, and 9 had small VMs $(<1.5 \mathrm{~cm})$. The smallest lesion treated measured $0.5 \times 0.5$ $\mathrm{cm}$, and the largest lesion was $8.5 \times 5.5 \mathrm{~cm}$. Mean size of the lesion was $3.8 \mathrm{~cm}$ with a standard deviation (SD) of $2.02 \mathrm{~cm}$. The portions of the tongue most frequently involved were the lateral aspects ( 22 of $44 ; 50 \%$ ), followed by the anterior aspect ( 15 of 44 ; $34 \%$ ). Four $(9 \%$ ) patients had involvement of the posterior aspect of the tongue, two (5\%) ventral aspect involvement, and the VM was diffuse in one (2\%) patient ( - Fig. 4).

The number of treatment sessions ranged from 1 to 7 . The median number of treatment sessions for the different portions of the tongue was one. There was no significant difference $(p=0.38)$ in the number of treatment sessions based on the location of the lesion. Half of the study population (22 of 44) underwent only a single treatment session (-Fig. 5). For the large, medium, and small lesions, the median numbers of treatment sessions were 1,2 , and 1 , respectively. There was no significant correlation $(p=0.94)$ between the lesion size and the number of treatment sessions on Spearman's rank correlation test. The amount of sclerosant used varied from 0.5 to $12 \mathrm{~mL}$ (mean 3.72 .5 ).

Four patients received elective intubation in anticipation of airway obstruction. Of these four patients, only one patient

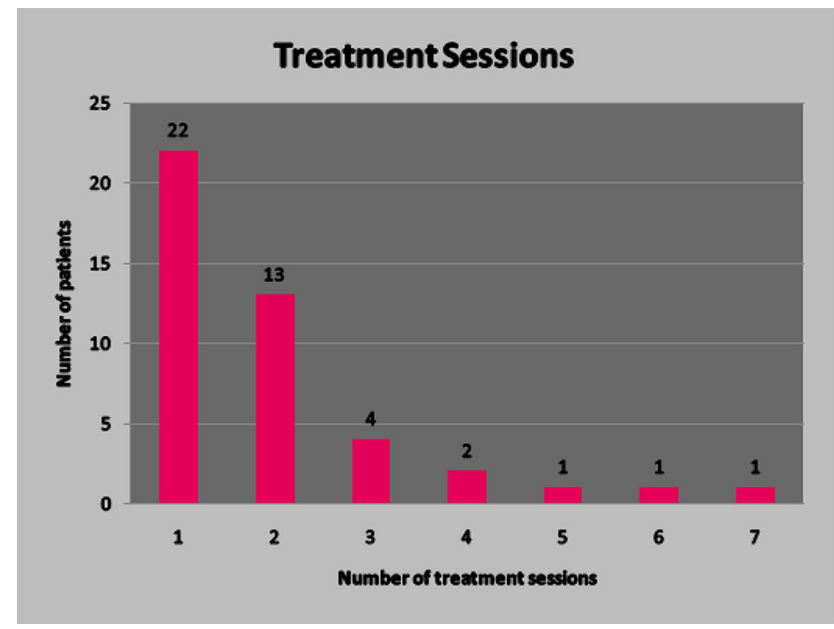

Fig. 5 Tongue VM: number of sclerotherapy sessions required for treatment.

who had large diffuse involvement of the tongue required prolonged intubation up to 72 hours due to significant postprocedure swelling. A transient increase in the lesion size

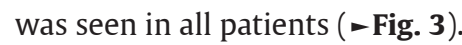

Follow-up was a challenge as most patients were from distant places. Of the 44 patients, 22 were seen in person, whereas 14 were reviewed through a telephonic conversation and graded for clinical improvement on a scale of 0 to 10 after 1 year. Eight patients were lost to follow-up ( - Table 2). Among 36 patients, 30 (83\%) had clinical improvement with sclerotherapy (-Table 3 ). The median clinical improvement was 4.5 on the 10-point scale, with a range of 1 to 8 . Twelve (12 of $36,33.3 \%$ ) patients demonstrated 1 to $40 \%$ improvement in the lesion size and 18 (50\%) had 41 to $80 \%$ improvement in the lesion size.

\section{Complications}

Complications were noted in four (9\%) patients. Two patients had minor complications whereas two had major complications ( - Table 4 ).

\section{Discussion}

In our study, sclerotherapy of the VM of the tongue with $3 \%$ STS was found to be effective in majority (30 of 36, 83\%) of the patients. No patient reported worsening of symptoms during follow-up.

We have used 3\% STS in all the patients. STS has relatively smaller incidence of major complications as compared with a more potent sclerosant, absolute alcohol. ${ }^{12}$ Bleomycin is the other choice of sclerosant with reportedly less post-treatment swelling. ${ }^{13,14}$ However, a risk of pulmonary fibrosis is associated with bleomycin, which has been mainly studied regarding chemotherapy.

The amount of endothelial effect and subsequent inflammation should ideally be such that the VM should be sclerosed with minimum number of treatment sessions. At the same time, the swelling caused as a component of 
80 STS Sclerotherapy for Tongue VM Inbaraj et al.

Table 2 Tongue VM: posttreatment follow-up of individual patients

\begin{tabular}{|c|c|c|c|}
\hline Age $(y)$ & Sex & Region of tongue involved & Improvement posttreatment (scale 1-10) \\
\hline 17 & M & Anterior & NO \\
\hline 36 & M & Anterior & NO \\
\hline 21 & M & Ventral & 5 \\
\hline 7 & $\mathrm{~F}$ & Lateral & 7 \\
\hline 63 & M & Lateral & 3 \\
\hline 29 & $\mathrm{~F}$ & Anterior & 0 \\
\hline 43 & $\mathrm{~F}$ & Lateral & No \\
\hline 11 & M & Lateral & 0 \\
\hline 39 & M & Lateral & 0 \\
\hline 20 & $\mathrm{~F}$ & Posterior & 5 \\
\hline 27 & $\mathrm{M}$ & Anterior & 3 \\
\hline 30 & $\mathrm{M}$ & Ventral & 7 \\
\hline 23 & $\mathrm{M}$ & Lateral & 3 \\
\hline 9 & $M$ & Anterior & 7 \\
\hline 52 & $\mathrm{~F}$ & Anterior & 0 \\
\hline 21 & $M$ & Anterior & No \\
\hline 46 & $\mathrm{M}$ & Lateral & 4 \\
\hline 34 & $\mathrm{M}$ & Lateral & 2 \\
\hline 46 & $\mathrm{~F}$ & Lateral & 5 \\
\hline 62 & $\mathrm{~F}$ & Anterior & No \\
\hline 15 & $\mathrm{M}$ & Anterior & 8 \\
\hline 40 & $\mathrm{~F}$ & Lateral & 2 \\
\hline 40 & $\mathrm{~F}$ & Lateral & 6 \\
\hline 11 & $\mathrm{M}$ & Posterior & No \\
\hline 53 & $\mathrm{M}$ & Lateral & 6 \\
\hline 30 & $\mathrm{M}$ & Lateral & 5 \\
\hline 7 & $\mathrm{M}$ & Anterior & 8 \\
\hline 36 & $\mathrm{~F}$ & Lateral & No \\
\hline 25 & $\mathrm{~F}$ & Lateral & 4 \\
\hline 16 & $\mathrm{M}$ & Anterior & 3 \\
\hline 32 & $\mathrm{~F}$ & Anterior & 7 \\
\hline 15 & $\mathrm{M}$ & Lateral & 1 \\
\hline 60 & $\mathrm{M}$ & Anterior & 4 \\
\hline 13 & $\mathrm{~F}$ & Posterior & 0 \\
\hline 22 & $\mathrm{~F}$ & Lateral & 5 \\
\hline 12 & $\mathrm{~F}$ & Anterior & NO \\
\hline 44 & $\mathrm{~F}$ & Lateral & 6 \\
\hline 17 & $\mathrm{M}$ & Anterior & 8 \\
\hline 23 & $\mathrm{M}$ & Anterior & 0 \\
\hline 24 & $\mathrm{M}$ & Lateral & 3 \\
\hline 9 & $\mathrm{M}$ & Lateral & 7 \\
\hline 33 & $\mathrm{~F}$ & Lateral & 6 \\
\hline 18 & $\mathrm{~F}$ & Posterior & 5 \\
\hline 24 & $\mathrm{M}$ & Lateral & 1 \\
\hline
\end{tabular}

Abbreviations: F, female; M, male; VM, venous malformation.

Note: The scale of improvement is based on $10=$ complete resolution, $0=$ no improvement, No = No follow-up available. 
inflammation should not result in complications. We believe the treatment effect is multifactorial, including the choice of sclerosant, volume of sclerosant, and dwell time of the sclerosant to act on the endothelial lining of the VM. Because we performed all the procedures under general anesthesia, tongue muscle relaxation would have contributed to better dwell time. Although the nature of the VM in the tongue is similar to the VMs elsewhere in the body, sclerotherapy of the tongue is challenging. While intubating the patient, the site of sclerotherapy needs to be discussed with the anesthetist, so that the endotracheal tube does not come in the way of sclerotherapy. It is a unique requirement to pull the tongue out to access the VM. We applied two different techniques as mentioned in the methodology. We avoided placing a suture to pull the tongue out if the anterior portion of the tongue was involved by the disease to prevent excess hemorrhage. When the patient is under anesthesia, muscle

Table 3 Tongue VM: outcome of sclerotherapy

\begin{tabular}{|l|l|}
\hline Treatment outcome & Number \\
\hline No improvement & 6 \\
\hline $0-1 \%$ improvement & 4 \\
\hline $21-40 \%$ improvement & 8 \\
\hline $41-60 \%$ improvement & 10 \\
\hline $61-80 \%$ improvement & 8 \\
\hline $81-100 \%$ improvement & 0 \\
\hline Lost to follow-up & 8 \\
\hline
\end{tabular}

Abbreviation: FVM, venous malformation. relaxation is an advantage, which results in enlargement of the lesion, facilitating better placement of the needles and also increasing the dwell time. Sometimes it may be difficult to use US guidance for accurate placement of the needles because of the limited place to keep both the probe and needle. In such situations, one could use US to locate the abnormal region and then puncture the lesion with the needle without real time US guidance and depend on the backflow of the blood to the needle to ensure proper placement of the needle tip within the venous space. Furthermore, this could be confirmed by venography. Proximity to the airway, especially when the posterior part of the tongue is involved, makes a huge difference, when compared with a similar VM in the extremity.

We encountered only a few complications, which occurred in $4(9 \%)$ of 44 patients. In only one patient, there was profuse bleeding from the tongue when silk thread was used to pull the tongue out. This particular complication, though extremely rare, should be kept in mind, and backup facilities such as transarterial embolization and surgery should be available. Hematuria was seen in only one patient, which could be due to relatively smaller amount of STS used in each sclerotherapy. Severe swelling and compromise of the airway requiring prolonged intubation was observed in one patient, who had a large and diffuse VM of the tongue. Need for emergency tracheostomy has been reported by other authors, ${ }^{15}$ who also noted that the lesions located posteriorly are at higher risk of complication. If a higher chance of airway compromise is anticipated, even a prophylactic tracheostomy may be considered..$^{15}$ An unusual case of development of

Table 4 Tongue VM: details of the complications

\begin{tabular}{|c|c|c|c|c|}
\hline Presentation & Treatment & Complication & Management & Outcome \\
\hline \multicolumn{5}{|c|}{ Minor complications } \\
\hline $\begin{array}{l}\text { 1. A } 17 \text {-year-old boy } \\
\text { with multiple vesicles } \\
\text { and fissures over the } \\
\text { tongue } \\
\text { (SIR grade B) }\end{array}$ & $2 \mathrm{mLSTS}$ & $\begin{array}{l}\text { Significant swelling } \\
\text { postprocedure with } \\
\text { continuous slow } \\
\text { bleeding }\end{array}$ & $\begin{array}{l}\text { Compression for } 1 / 2 \mathrm{~h} \\
\text { over the site of needle } \\
\text { insertion; antibiotics and } \\
\text { steroids }\end{array}$ & $\begin{array}{l}\text { The bleeding stopped and } \\
\text { swelling gradually subsided }\end{array}$ \\
\hline $\begin{array}{l}\text { 2. A 7-year-old girl with } \\
\text { swelling of tongue } \\
\text { (SIR grade B) }\end{array}$ & $11 \mathrm{~mL}$ STS & $\begin{array}{l}\text { Hematuria secondary } \\
\text { to hemolysis and } \\
\text { urinary excretion of } \\
\text { excess hemoglobin }\end{array}$ & $\begin{array}{l}\text { Good hydration with } \\
\text { IV fluids and } N \text {-acetyl } \\
\text { cysteine }\end{array}$ & $\begin{array}{l}\text { Hematuria resolved the } \\
\text { next day }\end{array}$ \\
\hline \multicolumn{5}{|c|}{ Major complications } \\
\hline $\begin{array}{l}\text { 3. A } 30 \text {-year-old man } \\
\text { with difficulty in speech } \\
\text { and swallowing } \\
\text { (SIR grade C) }\end{array}$ & $4 \mathrm{~mL} \mathrm{STS}$ & $\begin{array}{l}\text { Profuse bleeding as } \\
\text { the suture used to } \\
\text { anchor the tongue, } \\
\text { cut through the } \\
\text { tongue }\end{array}$ & $\begin{array}{l}\text { On-table transarterial } \\
\text { embolization of bilater- } \\
\text { al lingual arteries was } \\
\text { unsuccessful in controlling } \\
\text { the bleeding; emergency } \\
\text { surgical exploration and } \\
\text { suturing was performed }\end{array}$ & $\begin{array}{l}\text { The bleeding stopped with } \\
\text { suturing and patient recov- } \\
\text { ered completely }\end{array}$ \\
\hline $\begin{array}{l}\text { 4. A 9-year-old girl with } \\
\text { swelling of the tongue } \\
\text { leading to difficulty in } \\
\text { closing the mouth } \\
\text { (SIR grade D) }\end{array}$ & $5 \mathrm{~mL} \mathrm{STS}$ & $\begin{array}{l}\text { Significant swell- } \\
\text { ing postprocedure } \\
\text { requiring prolonged } \\
\text { intubation for } 3 \\
\text { days }\end{array}$ & $\begin{array}{l}\text { Steroids, IV antibiotics, } \\
\text { local ice packs, NG feeds }\end{array}$ & $\begin{array}{l}\text { The swelling decreased; the } \\
\text { patient was extubated and } \\
\text { recovered completely }\end{array}$ \\
\hline
\end{tabular}

Abbreviations: IV, intravenous; NG, nasogastric; SIR, Society of Interventional Radiology; STS, sodium tetradecyl sulfate; VM, venous malformation. 
squamous cell carcinoma of the tongue after sclerotherapy for the VM has been reported. ${ }^{16}$

The published literature on sclerotherapy of tongue VMs are part of a spectrum among VMs in broader locations such as the head and neck or isolated case reports. ${ }^{15,17}$ There is need for prospective studies on sclerotherapy of the tongue with long-term follow-up.

There are many limitations to our study. First, this is a retrospective single-center study with a relatively small number of patients. Second, the follow-up is limited with a large number of patients followed only through telephonic interview. Many patients had only a single sitting of injection, which could be attributed either to financial constraints, distance, or satisfaction with partial improvement. Most of the follow-up was only clinical, without imaging; hence a comparative volumetry could not be performed.

\section{Conclusion}

Tongue VMs pose unique challenges for treatment, including proximity to the airway and difficulties with anesthesia. Percutaneous sclerotherapy with $3 \%$ STS is a simple, safe, and effective treatment for these patients. When the lesion is diffuse, one must be aware of airway compromise and be prepared for prolonged intubation.

\section{Source of Funding}

None.

\section{Conflicts of Interest \\ None.}

\section{Declaration}

The manuscript has been read and approved by all the authors, the requirements for authorship as stated have been met, and each author believes that the manuscript represents honest work. The authors alone are responsible for the contents and writing of the manuscript.

\section{References}

1 Spence J, Krings T, terBrugge KG, da Costa LB, Agid R. Percutaneous sclerotherapy for facial venous malformations: subjective clinical and objective MR imaging follow-up results. AJNR Am J Neuroradiol 2010;31(5):955-960
2 Zheng JW, Mai HM, Zhang L, et al. Guidelines for the treatment of head and neck venous malformations. Int J Clin Exp Med 2013;6(5):377-389

3 de Lorimier AA. Sclerotherapy for venous malformations. J Pediatr Surg 1995;30(2):188-193, discussion 194

4 Mulliken JB, Young AE. Vascular Birthmarks: Hemangiomas and Malformations. Philadelphia, PA: Saunders; 1988

5 Sitra G, Kayalvizhi EB, Sivasankari T, Vishwanath R. A new venture with sclerotherapy in an oral vascular lesion. J Basic Clin Pharm 2014;6(1):40-43

6 Johnson PL, Eckard DA, Brecheisen MA, Girod DA, Tsue TT. Percutaneous ethanol sclerotherapy of venous malformations of the tongue. AJNR Am J Neuroradiol 2002;23(5):779-782

7 Duffy DM. Sclerosants: a comparative review. Dermatol Surg 2010;36 (Suppl 2):1010-1025

8 Pappas DC Jr, Persky MS, Berenstein A. Evaluation and treatment of head and neck venous vascular malformations. Ear Nose Throat J 1998;77(11):914-916, 918-922

9 Wiegand S, Eivazi B, Zimmermann AP, Sesterhenn AM, Werner JA. Sclerotherapy of lymphangiomas of the head and neck. Head Neck 2011;33(11):1649-1655

10 Tessari L, Cavezzi A, Frullini A. Preliminary experience with a new sclerosing foam in the treatment of varicose veins. Dermatol Surg 2001;27(1):58-60

11 Sacks D, McClenny TE, Cardella JF, Lewis CA. Society of Interventional Radiology clinical practice guidelines. J Vasc Interv Radiol 2003;14(9 Pt 2):S199-S202

12 Alakailly X, Kummoona R, Quereshy FA, Baur DA, González AE. The use of sodium tetradecyl sulphate for the treatment of venous malformations of the head and neck. J Maxillofac Oral Surg 2015;14(2):332-338

13 Ul Haq F, Mitchell SE, Tekes A, Weiss CR. Bleomycin foam treatment of venous malformations: a promising agent for effective treatment with minimal swelling. J Vasc Interv Radiol 2015;26(10):1484-1493

14 Horbach SE, Lokhorst MM, Saeed P, de Goüyon Matignon de Pontouraude CM, Rothová A, van der Horst CM. Sclerotherapy for low flow vascular malformations of the head and neck: a systematic review of sclerosing agents. J Plast Reconstr Aesthet Surg 2016;69(3):295-304

15 Bourgouin P, Thomas-Chaussé F, Gilbert P, et al. Effectiveness and safety of sclerotherapy for treatment of low-flow vascular malformations of the oropharyngeal region. J Vasc Interv Radiol 2018;29(6):809-815

16 Chen G, Cai X, Ren J-G, Jia J, Zhao YF. Unexpected development of tongue squamous cell carcinoma after sclerotherapy for the venous malformation: a unique case report and literature review. Diagn Pathol 2013;8:182

17 Shah KM, Karagir A, Adaki S. Slow-flow-type venous malformation of tongue. BMJ Case Rep 2013;2013:bcr2013008945 